\title{
A ARTE DE CURAR E A ARTE DE CUIDAR: A MEDICALIZAÇÃO DO HOSPITAL E A INSTITUCIONALIZAÇÃO DA ENFERMAGEM*
}

\author{
Eliete Maria Silva** \\ Regina Aparecida Garcia de Lima** \\ Silvana Martins Mishima**
}

\begin{abstract}
RESUMO: Trata-se de uma reflexão crítca sobre o cuidar e o curar, numa perspectiva histórica. A racionalidade científica na enfermagem engendrou-se no movimento de medicalização do hospital enquanto espaço terapêutico e de desenvolvimento de uma tecnologia e saber médicos. A institucionalização da profissão constituiu-se em duas perspectivas: a moral-disciplinar e a técnica. A configuração de uma "crise profissional" é apontada em relação à formação, mercado de trabalho, prática profissional, organização e sindicalização e pesquisa em suas articulações dinâmicas na sociedade em que estão inseridas. Atualmente, a manutenção e prolongamento da vida encaminham para projetos de maior qualidade dos cuidados e da própria vida, em termos pesoais e profissionais.
\end{abstract}

\begin{abstract}
It is a critical reflection about the care and the cure, in a historical perspective. The scientific rationality in nursing engendered in the movement of transformation of the hospital as a therapeutic space and the development of medical knowledge and technology. The institucionalization of nursing occurred in two perspectives: moral and technical. The configuration of the "professional crisis" is pointed out in relation to formation, labour market, practice, organization and research in its dynamic articulations in the society. Actually, the maintenance and prolongation of the life has been emphasized to projects directed of better quality of the care and the life, in personal and professional terms.
\end{abstract}

\section{INTRODUÇÃO}

O Homem enquanto parte da natureza, em um movimento recíproco/mútuo de transformação, atua sobre ela, em função de suas necessidades, de forma a perpetuar-se e objetivar-se como espécie biológica e ser social. Contudo esta objetivação do homem não se limita à imediatez das situações com que se depara, uma vez que é capaz de produzir universalmente (para além de si e de seus próximos), não se restringindo portanto às necessidades mais imediatas.

Chamamos de movimento recíproco de transformação ao processo de produção e reprodução do próprio homem, à produção da existência humana, onde ao alterar a natureza com sua ação, o homem transforma a si próprio, havendo um permanente pro- cesso de construção/reconstnução do homem.

É um processo de produção da existência humana, porque o homem não só cria artefatos, instrumentos, como também desenvolve idéias (conhecimentos, valores, crença) e mecanismos para sua elaboração... (3:12)

Neste sentido, as idéias são produtos, e ao mesmo tempo, exprimem relações que o homem estabelece com a natureza. Dentre as idéias produzidas, estão presentes aquelas que dizem respeito ao conhecimento referente ao mundo, conhecimento este que irá se apresentar sob diferentes formas, exprimindo o contexto filosófico-social-cultural-político-econômico de momentos históricos determinados.

\footnotetext{
* Trabalho apresentado como tema livre no $44^{\circ}$ Congresso Brasileiro de Enfermagem, Brasilia D.F., 4 a 9 de outubro de 1992.

** Professoras Assistentes da Escola de Enfermagem de Ribeirão Preto, USP.
} 


\begin{abstract}
A ciência é uma das formas de conhecimento produzido pelo homem no decorrer de sua história. Portanto, a ciência também é determinada pelas necessidades materiais do homem, em cada momento histórico, ao mesmo tempo que nelas interfere. (3:15)
\end{abstract}

Desta forma o entender e o explicar racional se alteram na história, refletindo o desenvolvimento e rupturas ocorridas nos diferentes momentos da história da humanidade, sendo que a mudança de concepções implica em uma nova forma de ver a realidade, novo modo de atuação para obtenção do conhecimento, transformações no próprio conhecimento, mudando portanto a forma de interferir na realidade. Assim a busca de elaborar o pensamento racional tem marcas próprias em cada período.

Não apenas o homem contemporâneo produz ciência, sociedades primitivas produziram conhecimento. A ciência caracteriza-se por ser a tentativa do homem entender e explicar racionalmente a natureza, buscando formular leis que, em última instância, permitem a atuação humana.

Não só o conhecimento científico, mas também as técnicas pelas quais ele é produzido, as tradições de pesquisa que o produzem e as instituições que as apoiam, tudo isso muda em resposta a desenvolvimentos nelas e no mundo social e cultural a que pertencem ${ }^{(8)}$.

A razão na história nos remete a considerações de que não existe uma razão única, ou uma história única.

A história é olhada e perscrutada de distintas formas em momentos distintos do estado-da-arte da razão, da ciência e da tecnologia.

Ciência e tecnologia não são a mesma coisa, mas sim "parceiras". Na história, por um largo período, o domínio do intelectual (conhecimento científico) e o campo do manual/artesanal (técnico) seguiram caminhos separados.

Com a revolução galilaica, passam a ser relevante para a ciência, os ef eitos que esta se torna capaz de produzir; o conhecimento torna-se operacional, superando a racionalidade prioritariamente contemplativa.

Especialmente a partir do final do século XIX, passa-se a registrar um intercâmbio sistemático entre as atividades científicas e as tecnológicas. Por isso, é possível hoje reconhecê-las como parceiras.
Para os antigos a técnica não era um saber racional, ligava-se à arte. Associava-se à técnica uma forte dimensão social, um hábito, uma disposição criadora adquirida: "Como um produto característico da cultura em que é engendrada, elemento de constituição do mundo enquanto mundo humano". (12:21)

Mesmo após todo o intercâmbio, presente hoje na relação conhecimento científico e tecnologia, este segundo pólo sempre trazalgo de artesanal e intuitivo, a incorporação de tradições, experiências, de um saber-fazer.

A maioria das grandes doutrinas filosóficas tiveram que encarar a oposição entre a idéia definida, clara, esquemática (matemática e/ou logicamente) e o concreto, o acontecimento, o fato sempre pleno de sua historicidade, sua singularidade, cujo conhecimento (em nenhum momento) poderá nos oferecer uma imagem completa, um esquema do mesmo em sua essência/existência.

A opção original da Ciência pelo imutável possibilitou inegáveis avanços. Porém, nas mudanças e transformações biológicas e humanas, permanece a necessidade da conquista do tempo e da sua racionalidade.

O homem em sua materialidade/espirituosidade "inventa e cria" a matemática e a história. O condicionamento determinado do real, factual da matéria está em constante enf rentamento com o poder criador e libertário do espírito humano.

O conhecimento possível é sempre aproximado, sempre provisório, passível de modificações, quando novas informações sejam acrescentadas, ou mesmo, quando as informações já antes conhecidas sejam recolocadas, olhadas sob um novo prisma

Re-contar a história, buscando reconhecer a racionalidade presente, pode ser uma tentativa de abstrair sua evolução, de reconhecer sua ordem, de saber as opções/valorações que fizemos e, principalmente, é uma tentativa (novamente!) de considerar a história numa concepção de construção e transformação do mundo humano.

Pensamos em desenvolver este estudo em três momentos: primeiro fazendo uma recuperação da arte de cuidar e da arte de curar, depois vamos tratar do hospital e por último da enfermagem. 


\section{A HISTÓRIA DA RELAÇÃO ENTRE O CUIDAR E O CURAR}

O cuidado faz parte das necessidades básicas para a sobrevivência da vida humana. Inclusive o mundo que o homem construiu para si demanda cuidados: o fogo, as plantas, os instrumentos de trabalho, os animais domésticos etc.

Muito atrás no passado, a divisão sexual do trabalho colocava dois aspectos de particular importância:

- uma expectativa sobre os homens de cuidar do território, repelir o inimigo, proteger as mulheres e crianças e os pertences do grupo;

- uma expectativa sobre as mulheres de cuidar das crianças e das mães, de assegurar e manter a continuidade da vida humana.

Através das atividades de caça e guerra, os homens desenvolveram habilidades de lidar com ferimentos, acidentes, torceduras, ossos quebrados, habilidades "ortopédicas" e "cinúrgicas". As mulheres, ligadas ao nascimento, responsabilizaram-se por aspectos relativos à fertilidade: a criação de recém-nascidos, alimentação e cuidados das crianças. Também a morte relaciona-se ao nascimento, as mulheres davam suporte em situações de doenças, cuidam dos idosos e moribundos.

Um outro papel relevante nesse contexto é o do xaman, que desenvolvendo um papel religioso, manteve hábitos no sentido de preservar a fé e confiança nos grupos humanos. Por essa ocasião o mundo era povoado e controlado por espíritos e forças espirituais ocultas. A magia consistia em submeter estas forças e persuadir os espíritos a cooperarem. O xaman é apontado como o mediador das relações entre os homens (e mulheres) com o universo, as coisas, animais os eventos naturais.

Os rituais religiosos desenvolveram-se, c nesse contexto, inicia-se a escrita. Com o desenvolvimento da escrita, os religiosos adquirem um papel dominante, assumindo a responsabilidade de definir o que é BOM e CERTO e o que é ERRADO.

A partir do século $\mathrm{V}$ inicia-se um novo tempo, um novo mundo, no qual a Igreja organiza e produz um imaginário social que lhe garanta o real domínio ideológico e político. Deste papel religioso engendraram-se as profissões de padres, médicos e juízes, os quais em conjunto decidiam (e decidem!) a ordem social.
A prática das mulheres baseava-se em atividades de cuidado em duas direções:

- o cuidado do corpo - com contato direto com este, usando principalmente os sentidos do olfato e do tato, centrado na puberdade, gravidez, nascimento, parto, sensibilização, massagens, banho, aumento da sensibilidade e e emoções, inclusive sensações sexuais, práticas estéticas e de respeito/cuidado do corpo enquanto "casa do espírito", enquanto autoimagem que possibilita o seu próprio reconhecimento por outros e enquanto pertencente a um determinado grupo; $\mathrm{e}$

- o cuidado da alimentação - no intuito de prover alimentos, descobriram recursos em seus ambientes e inteiraram-se de todos os tipos de plantas (e seus cultivos). Em sua manipulação, desenvolveram, além do conhecimento de preparo de refeições, também, sobre algumas propriedades medicinais específicas.

Este conhecimento, baseado em habilidades, produziu um corpo de fatos empíricos a partir da observação acurada e concreta, sendo entretanto desvalorizado e taxado pela ciência racional como "não-científico". Segundo COLLIERE (5), com o desenvolvimento da escrita e seu uso exclusivo pelos sacerdotes, é que os homens começaram a confiscar o conhecimento feminino. Por séculos foi barrado o acesso da mulher à escrita. Os preceitos e regras das várias doutrinas, bem como, a base do conhecimento acadêmico da medicina, guardou para o conhecimento empírico do cotidiano do cuidado feminino, um status de trabalho manual e a-científico.

O desenvolvimento do Cristianismo e a institucionalização do papel feminino das irmãs de caridade, mudou a relação com o cuidado e teve efeitos profundos no futuro da humanidade. Algumas questões são especialmente significativas.

- a fé num Deus único (à imagem do homem);

- a superioridade do espírito sobre o corpo;

- o desprezo da vida;

- o corpo como a fonte de tudo o que é diabólico e pecaminoso, sendo exaltada a virgindade para as mulheres.

As irmãs de caridade tinham como responsabilidade dar cuidados espirituais e proteger a integridade corporal pela castidade e pureza, a exortação e aconselhamento tomaram o lugar das práticas ditas com o corpo tais como os banhos e massagens. 
O sofrimento corporal era valorizado, podendo ser aliviado, mas nunca evitado completamente. Além do respeito à pobreza material valorizava-se também a pobreza de conhecimento. Servir e obedecer conformaram um comportamento ditado por regras.

Nesse movimento de desenvolvimento do Cristianismo, vai sendo claramente introduzida a separação entre o cuidar e o curar.

É no final do século XVIII, em especial, que se inicia a institucionalização do hospital enquanto espaço médico - "locus" e instrumento - da arte de curar, e da enfermagem, cujo treinamento sc dirige para a obediência e/ou tentativa de respostas às expectativas do modelo médico (enquanto conhecimento e autoridade),em duas perspectivas principais: a moral-disciplinar e a técnica.

\section{A MEDICALIZAÇÃO DO HOSPITAL}

A prática do cuidado, que nos remete a atitudes e sentimentos presentes numa relação interpessoal impregnada de responsabilidades, inquictação do espírito, desvelo por outrem, cra comandada por representações simbólicas ligadas à religião, principalmente até o século XVII. (13)

O hospital, até meados do século XVIII, permaneceu como prática independente da medicina. Este espaço até então era comandado pelo pessoal religioso, raramente leigo, que cuidava do cotidiano hospitalar, da assistência alimentar dos internados, e da salvação, tanto dos pobres, moribundos, doentes, loucos e excluídos, quanto do próprio pessoal que deles cuidava. As dimensões filantrópica c caritativa eram a tônica desse "cuidar" quase "doméstico". O hospital era um misto de exclusão, assistência e transformação espiritual.

Segundo FOUCAULT (6), a medicina dos sćculos XVII e XVIII era profundamente individualista, tanto na formação quanto na prática. O papel do médico, aprendido de tcxtos e receitas transmitidas (às vezcs de um modo secreto), cra o de aliado da natureza $\mathrm{c}$ árbitro $\mathrm{cm}$ sua luta contra a doença. $\mathrm{O}$ médico devia observar a docnça c o docnte para descobrir o momento da crisc, do afrontamento entre a natureza (sadia) do indivíduo c o mal. Scu propósito cra favorecer a melhor atuação possível da natureza para vencer a doença.

A perspectiva de acompanhamento cra cxpectantc e passiva. A intervenção contra a docnça, na Idade Média, deslocou-sc para o acompanhamento solidá- rio do transe para a morte e o paraíso. (11)

Além da prática dos cirurgiões barbeiros, que continuavam suas intervenções no externo do corpo, a medicina do interno do corpo teve na Idade das Trevas um desenvolvimento tecnológico relativamente escasso.

O hospital, com a ampliação dos espaços urbanos e a emergência do mercantilismo, passa a ser denunciado como um foco de desordens, na medida em que espalha doenças em seu espaço intemo e na cidade, sendo ainda um foco de desordens econômicas, pelo tráfico intenso de mercadorias, objetos preciosos, matérias raras, especiarias, etc. A possibilidade de, fingindo-se enf crmo escapar da alfândega, colocou para as autoridades a necessidade de disciplinar os hospitais marítimos e a quarentena.

Outro aspecto relevante no período de transformação do hospital foi a "mutação técnica do exército", com o surgimento do fuzil que demandava exercício e adestramento para seu manuseio. Passou a não ser suficicnte ter dinheiro pra se formar um exército - o custo de um soldado se incrementa. Os hospitais militares passam a ter três preocupações centrais:

- vigiar para evitar deserção;

- curar, evitando que morressem por doença; e

- controlar para que não se fingissem doentes para permanecer acamados quando curados.

\section{A disciplina é a tecnologia então privilegiada.}

No esquadrinhamento urbano que é próprio desse período, o discurso médico aponta o hospital como causa de doença e mesmo de morte. A elaboração de um conhecimento dos fatores relativos a isso ligam-se ao clima, à geografia, às relações do homem com o meio ambiente.

As regras da Higiene encaminham uma transformação do hospital em lugar de cura e local de aprendizagem e produção do saher médico (9).

Os mecanismos (disciplinares) utilizados perpas$\operatorname{sam}^{(6)}$ :

- a distribuição cspacial dos indivíduos;

- o acompanhamento da evolução dos doentes e feridos (o controle passa a incluir os gestos, o desenvolvimento do trabalho $\mathrm{c}$ não só scus resultados);

- a vigilância constantc do pessoal que trabalha nos hospitais (c aqui cntra a institucionalização da cnfermagem): 
- o registro contínuo dos pacientes e em suas papeletas: nome, idade, condição, profissão, dia de entrada, dietas, medicamentos internos e externos e o diagnóstico.

Além de responder às necessidades do cuidado $\mathrm{e}$ da cura, estas informações vão proporcionar o acompanhamento, a elaboração de estatísticas, acúmulo de experiências e produção/transmissão de conhecimentos médicos. $\mathrm{O}$ acompanhamento dos doentes e, principalmente, dos mortos, que são freqüentemente necropsiados, visa à classificação, ao relato e compreensão científica do caso e de sua evolução.

O saber médico, a partir do século XVIII, passa a estar no cotidiano hospitalar. Tanto a população, quanto o indivíduo, são objetos da intervenção médica. O meio que circunda o doente (e a população): o ar, a água, a temperatura ambiente, o regime de sono, a alimentação, é esquadrinhado, no intuito de encaminhar a melhor resolução da doença enquanto fenômeno natural, que obedece às leis naturais.

Alguns fatos são apontados para o movimento de constituição da Medicina enquanto um campo de conhecimento de práticas ef etivas e resolutivas em termos individuais e sociais. Além da medicalização do hospital que viabilizou, a nível institucional e cultural, o desenvolvimento da Clínica, são também relevantes, o que CANGUILHEM ${ }^{(4)}$ chama de persistência e desenvolvimento de uma atitude ponderada de cepticismo terapêutico, e o advento da fisiologia como disciplina médica autônoma, relativamente à anatomia clássica.

As necessidades sociais, colocadas pela sociedade industrial, de contar com corpos humanos sadios que adquirem um novo significado como portadores de uma energia potencial para o trabalho, o princípio da igualdade social (da Revolução Francesa, 1789), e o direito ao consumo como parte da constituição dos direitos de cidadania, conforme apontado por MENDES-GONÇALVES (10), estão presentes na reorganização e desenvolvimento do trabalho em saúde nas sociedades capitalistas, que se orienta ao redor de três eixos:

- como forma de controlar a doença em escala social ampla e ef etiva;

- como forma de recuperar a força de trabalho (civil e militar); e

- como forma de ampliar efetivamente os direitos (especialmente de consumo) das classes subalternas.
A instituição hospitalar, em seu caráter de instrumento do trabalho médico, demandou o desenvolvimento de uma coleção de trabalhos e trabalhadores. Vamos nos deter a seguir ao desenvolvimento da enfermagem.

\section{A INSTITUCIONALIZAÇÃO DA ENFERMAGEM}

É no bojo da dicotomia entre o cuidar e o curar, do desenvolvimento da ciência médica, da constituição das sociedades capitalistas, que a enfermagem se institucionaliza.

O treinamento profissional baseava-se em seu papel disciplinador e na organização infra-estrutural de um espaço para o desenvolvimento das práticas $\mathrm{e}$ do conhecimento médico. COLLIERE ${ }^{(5)}$ coloca que, apesar de Florence Nightingale publicar que o treinamento das mulheres deveria ser no sentido de dar cuidados adequados de enfermagem, baseados em suas próprias observações, conhecimento e práticas, o objetivo do treinamento enfocava o seu comportamento, o que era chamado de "papel das enfermeiras".

Nos países ocidentais a formação das enfermeiras foi implementada no sentido de responder ao comportamento esperado pelas instituições e pelos profissionais médicos. Nenhuma questão sobre o significado do cuidado, quais os seus objetos, suas aproximações às chamadas necessidades do cotidiano, foram considerados.

A formação das enfermeiras construiu-se em duas perspectivas:

- a moral, diretamente associada às origens da assistência dada pelas irmãs de caridade, inclui coisas tais como devoção aos pacientes, dedicação, vocação, conduta correta, obediência e obrigação de servir aos médicos; a subordinação ao pensamento e conhecimento de outros dava a tônica de um trabalho baseado em regras; e

- a técnica, desenvolvida em parceria com os médi$\cos$, direcionou a prática da enfermagem a complementar os tratamentos e procedimentos médicos; o exíguo conhecimento ministrado limitava-se a organizar as rotinas e "como-fazer". Foram repassadas à enfermagem as atividades do trabalho médico, que mais do que ter um caráter intelectual, caracterizavam-se pelo desenvolvimento de habilidades manuais. 
A enfermagem passa então a desenvolver um trabalho subordinado e complementar ao ato/processo de cura, respondendo a uma necessidade social presente naquele momento.

Esta característica do trabalho feminino, subordinado ao conhecimento e autoridade médicos, convergiu para uma imagem social desvalorizada da enfermagem, sem reconhecimento legal ou econômico. A manutenção dessa dependência por um largo período estruturou o que COLLIERE (5) chama de "invisible health care-providers".

Distanciando-nos da discussão do espaço que "se perdeu". enquanto mulheres e "cuidadoras" no desenvolvimento da racionalidade científica, bem como das práticas de saúde e de enfermagem, vamos olhar para a proposta que "deu certo", a institucionalização da enfermagem, a enfermagem moderna, como passou a ser chamada a partir de Florence Nightingale.

NIGHTINGALE (11:146) publicou em 1860, na Inglaterra vitoriana, sociedade expansionista, moralista, imperialista, progressista e industrial o "Notes on Nursing". Nele evidenciou a necessidade de uma preparação formal e sistemática das enfermeiras - que trabalhavam em residências ou em hospitais - como também exorta às mulheres, às professoras para o que é a Boa Enfermagem:

Comumente as mulheres alegam não poder saber nada sobre as leis da saúde, ou o que fazer para preservar a saúde de seus filhos, porque nada sabem de patologia, ou ainda, que nem podem fazer dissecação (...). A patologia ensina o mal que a doença causou. Nada mais além disso. Sobre o principio positivo, saúde, e o negativo, patologia, nada sabemos exceto o que aprendemos pela observação e pela experiência (grifo nosso). (...) tanto quanto sabemos, a medicina ajuda a natureza a remover a obstrução, nada mais além disso, e o que a enfermagem tem de fazer, em ambos os casos, é manter o paciente nas melhores condiçz̃es possiveis, a fim de que a natureza possa atuar sobre ele.

Convergente com a compreensão da doença enquanto um processo natural, a orientação dada era no sentido de que o trabalho da enfermeira viabilizasse as condições adequadas de arejamento, aquecimento, ruídos, iluminação, limpeza, higiene corporal, alimentar, e mesmo, de atividades e ânimo. Valorizando a observação empírica, Florence foi "expert" em questões administrativas e sanitárias e, enquanto precursora, viabilizou uma grande expansão desta proposta na enfermagem.

Procuramos reconhecer com este breve estudo a convergência de dois movimentos sociais: a medicalização do hospital e a institucionalização da enfermagem. É preciso continuar a tarefa, no sentido de nos aproximarmos da atualidade.

"A fase que vivenciamos é a do reconhecimento da enfermagem como ciência passando do factual para o conceitual". (2:44) Esta frase é bastante significativa para a reflexão proposta, pois retrata a questão colocada, no sentido de se tentar construir um "esforço coletivo" da enfermagem brasileira no intuito de elevá-la ao status de "ciência", cujo enfoque principal seria a busca de autonomia profissional e da especificidade de um corpo de conhecimentos próprios para a enfermagem.

Para melhor delimitação da problemática, parece-nos importante recuperar o saber de enfermagem, saber este construído e constituído segundo certa racionalidade, e que é considerado como o "instrumental que a enfermagem utiliza para realizar o seu trabalho, instnumental este legitimado e reproduzido pelo ensino desta prática". (1)

Assim a sistematização do ensino de enfermagem, nas primeiras décadas do século nos EUA, e que foi introduzida em outros países, inclusive para o ensino de enfermeiras no Brasil, se deu sobre três classes de conhecimentos básicos (1:30)

$$
\begin{aligned}
& \text { - princípios, fatos, instrução englobados } \\
& \text { na denominação de ciência de enferma- } \\
& \text { gem com ênfase na ciência biológica, fi- } \\
& \text { sica e social, ciência médica, sanitária e } \\
& \text { doméstica e assim por diante; } \\
& \text { - técnicas e habilidades especializadas, } \\
& \text { sendo que algumas das artes de enferma- } \\
& \text { gem são tipicamente manuais, outras so- } \\
& \text { ciais, intelectuais ou administrativas. Al- } \\
& \text { gumas são peculiares à enfermagem, ou- } \\
& \text { tras são empréstimos ou adaptaçðes das } \\
& \text { profissões médica, pedagógica, eclesiás- } \\
& \text { tica e artes domésticas e de muitas outras } \\
& \text { fontes; } \\
& \text { - ideais, a atitude social e padrão profis"- } \\
& \text { sional de conduta, englobados na deno- } \\
& \text { minação de ética de Enfermagem ou Es- } \\
& \text { pirito de Enfermagem. }
\end{aligned}
$$

Num primeiro momento respondendo a determinações da organização do trabalho em saúde e do 
contexto sócio-político-econômico, as técnicas de enfermagem evoluem fundamentalmente para, conforme ALMEIDA \& ROCHA ${ }^{(1: 56)}$

\section{dar conta em primeiro lugar não do obje- to da en fermagem, ou seja, o cuidado ao doente, mas para dar conta do aumento crescente dos cuidados de enfermagem devido ao grande número de internações e ao aumento de ações, que consideradas "manuais" passam das mãos dos médicos para as enfermeiras.}

$\mathrm{Na}$ década de cinqüenta surge a preocupação em organizar os princípios científicos que deveriam nortear a prática de enfermagem, até então vista como não científica e suas ações baseadas na intuição. A fundamentação deste saber é quase toda da medicina, agregando-se também a da psicologia e da sociologia. Neste mesmo período de organização dos princípios científicos, dá-se a ampliação de novas técnicas laboratoriais, terapêuticas, etc.

O saber produzido a partir da década de setenta irá caracterizar-se pela produção das Teorias de Enfermagem, numa busca da autonomia e da especificidade.

Através desta produção a enfermagem busca afirmar-se como ciência, no sentido de garantir a conquista da autonomia profissional, de valorização do status junto a outras profissões, ou seja, este saber estaria mais voltado a um "projeto ideológico" de cientificismo e autonomia da enfermagem. Na produção deste conhecimento, tem-se a agregação aos conhecimentos da biologia, fisiologia e medicina, os da psicologia, com ênfase nos aspectos comportamentais e de relações humanas e os da sociologia.

Desta forma, observa-se que a produção de conhecimentos na enfermagem volta-se para aspectos internos e técnicos da profissão. No final dos anos setenta e início dos oitenta, principia-se uma outra vertente de estudos cuja análise pauta-se na compreensão da enfermagem como prática social, buscando uma visão globalizante deste trabalho, inspirada no materialismo histórico, e explicitando as relações econômicas, políticas e ideológicas presentes.

Contemporaneamente vivemos uma diversificação de concepções, de modelos, de práticas, de tendências filosóficas, de processos... Nas palavras de ANGERAMI \& CORREIA ${ }^{(2: 44-45)}$

Este pluralismo da Enfermagem é, tam-
bém, resultado da cultura atual, onde já
não existe mais um monolitismo explica-
dor, mas várias possiveis explicações das realidades. Assim, já não há uma filosofia, mas várias filosofias, não há uma cultura, mas várias culturas, não há um centro de saber, mas vários centros de saber, já não já também, uma Enfermagem, mas várias enfermagens...

A enfermagem modema brasileira configura-se por problemas ligados à:

- Formação: englobando questões relativas à baixa procura e ingresso aos cursos de enfermagem. evasão durante o curso, queda gradativa do número de egressos, descompasso entre teoria e prática;

- Mercado de trabalho: onde se fazem presentes a evasão profissional, as dificuldades inerentes ao trabalho essencialmente feminino, condições de trabalho caracterizadas pela dupla jomada, presença de riscos ocupacionais de diferentes etiologias, falta de valorização traduzida na ausência de planos de cargos, carreira e salários, baixo status social, inserção de categorias profissionais sem qualificação específicas (atendentes e agentes de saúde);

- Prática profissional: inseridos aí questões como inadequação dos profissionais às exigências das instituições prestadoras de atenção à saúde. possibilidade restrita de ascenção a níveis decisórios. insatisfação dos profissionais em relação às atividades desenvolvidas, ausência de parâmetros para avaliação da assistência prestada, divisão parcelar do trabalho com restrita integração e cooperação, reduzido prestígio e credibilidade, deficiência nos mecanismos de controle e regulamentação profissional, dicotomia entre a assistência direta e o gerenciamento/administração em enfermagem;

- Organização e sindicalização: onde se detecta pequena aderência dos profissionais às instâncias participativas, baixa politização das categorias, falta de integração entre as distintas instâncias representativas;

- Pesquisa em enfermagem: ausência de políticas de investigação na área e dificuldades na obtenção de recursos, bem como restrito desenvolvimento de conhecimentos específicos, pequena divulgação do conhecimento constituído, retratado pelo reduzido número de publicações e periódicos, pouca utilização deste conhecimento na prática, limitada participação dos profissionais em eventos, reuniões científicas e núcleos de pesquisa, denotando uma pequena motivação para estas atividades. 
Esta abordagem da "crise da profissão", como inerente à própria profissão, tendo suas origens c possibilidades de solução presentes no interior da enfermagem, no seu desenvolvimento e competência técnica c científica, ainda é majoritária. A produção que articula a enfermagem enquanto um trabalho na dinâmica do setor saúde e da sociedade em geral, vem sendo paulatinamente desenvolvida.

O projeto de construção da ciência da enfermagem, que ambiciona a valorização de scu trabalho e "uma pretensa autonomia" de sua prática embaça a visão e se transforma em um verdadeiro mito, quando não considera as condições presentes no trabalho da enfermagem, suas relações com o trabalho em saúde, as determinações inerentes à constituição do mercado de trabalho, os modelos de assistência à saúde, as lutas internas dos agentes por uma atuação cooperativa no processo de trabalho, o quadro econômico-social e político das sociedades concretas.

\section{CONSIDERAÇÕES FINAIS}

\begin{abstract}
A história da verdade não é linear e monótona. (...) A história das ciências devia tornar-nos mais atentos ao facto de que as descobertas cientificas (acrescentamos também as tecnológcas!), numa certa ordem dos fenòmenos, podem assumir o papel de obstáculo, ao trabalho teórico (e prático!) em curso numa outra ordem, o que se deve ao facto da sua possivel de-
\end{abstract}

gradação em ideologias". (4:92)

Pois o atraso, tal como o progresso, é história, na história das ciências como em qualquer outro dominio". (4:93).

Os avanços científicos contemporâneos associados ao desenvolvimento econômico-político e tecnológico colocam novas necessidades sociais. A manutenção e o prolongamento da vida humana coloca a questão da qualidade de vida e qualidade do cuidado. A saúde e a enfermagem estão partilhando desta preocupação c construção do novo, no âmbito das relações homem-mulher, das instituições, da cultura, das sociedades...

Partilhando do pensamento de HOLDEN (8) de que, na dimensão do curar também se faz presente o cuidar, c que na dimensão do cuidar, o curar se encontra inserido, que são faces de uma mesma realidade na prática de saúde (médica e de enfermagem), consideramos que no estabelecimento de um projeto para a enfermagem se leve em conta a humanização deste curar e cuidar. que resgate o direito de cidadania de cada indivíduo, que tenha como perspectiva a saúde não simplesmente como ausência de doença, mas como mẹelhores condições de vida, onde o processo vital humano, a nível individual c coletivo, encontre-se prenhe de possibilidades e significados, preservando a humanidade em seu ambiente biológico e físico, como também histórico, cultural e social. A defesa da diversidade como valor pode impedir a construção de um mundo homogêneo, racionalmente trágico.

\section{REFERÊNCIAS BIBLIOGRÁFICAS}

1. ALMEIDA, Maria Cecilia P., ROCHA, Juan S. Yaslle. $O$ saber da enfermagem e sua dimensão prática. São Paulo: Cortez, 1986.

2. ANGERAMI, Emilia Luigia S., CORREIA, Francisco de Assis. Em que consiste a enfermagem. In: SEMINÁRIO NACIONAL: O PERFIL E A COMPETĖNCIA DO ENFERMEIRO, 1, Brasilia, 28 de setembro a 2 de outubro de 1987. Anais... Brasilia, Secretaria da Saúde/Fundação Hospitalar do Distrito Fe-deral, 1987, p.38-48.

3. ANDERY, Maria Amália et al. Para compreender a ciência. Rio de Janeiro: Espaço e Tempo, São Paulo: EDUC, 1988.

4. CANGUILHEM, Georges. Ideologia e racionalidade nas ciências da vida. Lisboa: Edições 70, s.d.

5. COLLIERE, Marie Françoise. Invisible care and invisible women as health care-providers. Int. J. Nurs. Stud., Great Britain, v.23, n.2, p.95-112, 1986.

6. FOUCAULT, Michel. Microfisica do poder. 9 ed. Org. e trad. Roberto Machado. Rio de Janeiro: Graal, 1990.

7. HOLDEN, Robyn J. In: Defence of cartesian dualism and hermeneutic horizon. Journal of Advanced Nurs. v.16, p. 1375-1381, 1991.
8. KNELLER, George F. A ciencia como atividade humana. Trad. José de Souza. Rio de Janeiro: Zahar, São Paulo: EDUSP, 1980.

9. MACHADO, Roberto et al. Danação da norma: medicina social e constituição da psiquiatria no Brasil. Rio de Janeiro: Graal, 1978.

10. MENDES-GONÇALVES, Ricardo Bruno. Processo de trabalho em saúde. Depto. Med. Prev. e Social Faculdade de Medicina. USP 1988 (datilografado). $31 \mathrm{p}$.

11. NIGHTINGALE, Florence. Notas sobre enfermagem: o que é e oque nãoé. Trad. Amália Correa de Carvalho. São Paulo: Cortez. Ribeirão Preto, ABEn/CEPEn, 1989.

12. PAUla E Silva, Evando Mirra de. Ensino tecnológico e universidade. Ciência Hoje. SBPC, v. 14, n. 79, p. 20-23, jan/fev 1992.

13. ROSSI, Maria José dos Santos. O curar e o cuidar - a história de uma relação (um ensaio) Rev. Bras. Enf. Brasilia, v. 44, n. 1, p. 16-21, jan/mar 1991 .

Recebido para publicação em 30.08.93. 